\title{
Nutritional Status and Feeding Practices of Children Aged 0 to 36 Months in Thulamela Municipality, Limpopo Province
}

Anzani Mugware ( $\square$ anzanimugware@gmail.com )

University of Venda

\section{Selekane Ananias Motadi}

University of Venda

Lindelani Fhumudzani Mushaphi

University of Venda

\section{Research Article}

Keywords: Breastfeeding, complementary feeding, and nutritional status

Posted Date: March 7th, 2022

DOI: https://doi.org/10.21203/rs.3.rs-1361972/v1

License: (c) (i) This work is licensed under a Creative Commons Attribution 4.0 International License.

Read Full License 


\section{Abstract}

Background: Poor Infant and young child feeding practices accounts for nutrients deficiency, illness and infections in children that lead to malnutrition at an early age. The objective of this study was to investigate the nutritional status and feeding practices of children aged 0 to 36 months in Thulamela Municipality.

Methods: A cross-sectional survey was conducted between September and December 2019 in Thulamela Municipality. A total number of 250 mother-child pair were recruited in the study using a convenience sampling technique. A structured questionnaire was used to interview mothers. Anthropometric measurements of children were assessed using standard procedure. Anthropometric measurements were calculated using WHO Anthro version 3.2.2. The data obtained were analysed using Statistical Package for Social Sciences (SPSS, Chicago, IL, USA) version 26.

Results: The mean ( \pm SD) age of children in months was 10.53 (8.39). Exclusive breastfeeding up to six months was practised by only $7.6 \%$ of mothers while $87.5 \%$ of mothers introduced complementary feeding before the age of six months. The prevalence of stunting, wasting and underweight were $9.2 \%$, $2 \%$ and $3.6 \%$ respectively. About $38.1 \%$ of children who received water before six months of age were more likely to be stunted as compared to their counterparts $(19.9 \%)(p=0.001)$. Children who were given complementary foods one week after birth, the odds of being underweight were 9.00 times as compared to those who were given complementary foods after six months ( $\mathrm{OR}=9.00 ; 95 \% \mathrm{Cl}=1.325-61.138)$.

\section{Introduction}

The first 1000 days of life, from conception to two years of age, is a critical window for the promotion of optimal growth, health, and development [1]. The World Health Organisation recommends early initiation of breastfeeding within an hour after delivery, exclusively breastfeeding for the first six months of life, followed by the introduction of complementary foods at six months while continuing breastfeeding at least two years or even beyond [2]. Globally, it is estimated that only $44 \%$ of infants are exclusively breastfed for the first six months of life while most children were introduced to solid, semi-solid or soft foods late or earlier than recommended [3]. In South Africa, exclusive breastfeeding remains very low with only $7.4 \%$ of children exclusively breastfed for the first six months while most of the children received solid food and fluids before the recommended age of six months [4]. In the previous study conducted in Limpopo Province, Dzimauli region found that less than $1 \%$ of children were exclusively breastfed for up to 3 months, but none of the children were exclusively breastfed for up to 6 months [5].

Poor breastfeeding and complementary feeding practices accounts for nutrients deficiency, illness and infections in children that lead to malnutrition at an early age [6]. Malnutrition in the early stage of life, has been directly linked with poor infant feeding practices, high rates of infectious diseases, especially in developing countries such as South Africa [5, 7]. Furthermore, malnutrition decreases a child's chance of survival, hampering ideal health, growth, and development [8]. Early childhood malnutrition leads to 
growth retardation, delaying of mental development and impairment of intellectual level [9]. The longterm effects of nutritional deficiencies have been established and these include compromised educational achievement, low economic productivity, reproductive outcomes, and overall health in adulthood which tends to be difficult to reverse later in life [8]. In 2015, the world agreed to eliminate all forms of malnutrition by 2030 [10]. To reduce malnutrition amongst children under five years, there is need to improve infant and young child feeding practices, since feeding practices is one of the most determinants of nutritional status of children.

Limpopo Province is experiencing high levels of child malnutrition, with $4.2 \%$ of children under the age of five years reported to have severe acute malnutrition [11]. In the recent study conducted in Limpopo Province, reported that $25.9 \%$ of children died as results of severe acute malnutrition [12]. The prevalence of underweight, stunting and wasting amongst children under five years in Limpopo Province was 5\%, $15.5 \%$ and $5 \%$ respectively [4]. Latest national survey reported that $22 \%$ of children under five years in Limpopo Province were stunted, indicating chronic malnutrition [13]. Inappropriate feeding practices such as early introduction of complementary foods and mixed feeding were identified as a major contributor to child malnutrition in Limpopo Province $[14,15]$. Therefore, it is important to investigate the nutritional status and infant feeding practices of children aged 0 to 36 months in Thulamela Municipality, Limpopo Province.

\section{Methods And Materials}

\section{Study population and design}

A cross-sectional study was conducted between September and December 2019 in Thulamela Municipality, which is one of four municipals in Vhembe District. All six local areas in Thulamela municipality were regarded as a cluster in the study. Simple random sampling was used to select three clinics per cluster to make a total of 18 clinics. Convenience sampling technique was used to select 250 mother-child pair aged 0 to 36 months during well-baby clinic visit. Children who were aged 0 to 36 months and whose parents consented and were present on the day of data collection were included in the study. Children who were severely ill were excluded from the study.

\section{Data collection}

Structured questionnaire was used to interview mothers on breastfeeding practices and complementary feeding practices. Anthropometric assessments were performed according to standard procedures as described by the International Society for the Advancement of Kin-anthropometry [16]. The following measurements were taken in duplicate with the children wearing light clothing and no shoes: standing height, length, and weight. Height was measured to the nearest $0.1 \mathrm{~cm}$ using a portable stadiometer; length was measured to the nearest $0.1 \mathrm{~cm}$ using a measuring board. Weight was measured to the 
nearest $0.01 \mathrm{~kg}$ on a calibrated portable Seca solar scale (model 0213) (Seca, Hammer Steindamm, Hamburg, Germany).

Anthropometrics indicators expressed as weight-for-age (WAZ), height/length-for-age (H/LAZ), weight-forheight/length (WH/LZ) and Body Mass Indices for age (BMI/A). Anthropometric status was interpreted using WHO child growth standards. Z-score classification cut-off point below -2SD for WAZ, WH/LZ, $\mathrm{H} / \mathrm{LAZ}$ referred as underweight, wasting, and stunting respectively [17]. In addition, the cut-off points below $-3 S D$ is referred severe underweight, severe wasting and severe stunting respectively. Furthermore, the cut-off points between $+2 S D$ to $<+3 S D$ for WH/LZ is referred as overweight while cut-off point above $>+3 S D$ is referred as obese.

The Minimum Dietary Diversity (MDD) of children was assessed using 24-hour recall method. Mothers were asked to recall all the foods that the child consumed during the previous 24 hours. The researcher used food cards to assist mothers to remember the food items they fed their children in the previous 24 hours [18]. The minimum dietary diversity (MDD) score was interpreted using the WHO recommended cutoff point with a value of " 1 " indicates if the child had consumed four or more groups of foods and " 0 " if less.

\section{Statistical analysis}

The data obtained were cleaned, coded, and entered in Microsoft (MS) Excel spreadsheet, then exported to IBM Statistical Package for Social Science version 26 for analysis (SPSS, Chicago, IL, USA). Anthropometric measurements were calculated using WHO Anthro version 3.2.2 [19]. Descriptive statistics was performed for all variables in the study. The categorical variables were presented as frequencies $(n)$ with percentage (\%) of the total study sample. Continuous variables were presented as mean \pm standard deviation (SD) for normally distributed data. Chi-Square test for the categorical variables was performed. The chi-square test used to discover the relationship between two categorical variables. Logistic regression analysis was performed to explore associations between nutritional status and feeding practices. The Odds Ratio (OR) together with their corresponding $95 \%$ confidence intervals was computed and interpreted accordingly. A P-value $<0.05$ was considered to declare a result as statistically significant in this study.

\section{Results}

A total number of 250 mother-child pair were recruited in the study. The mean ( \pm SD) age of children in months was $10.53( \pm 8.39 S D)$. Most $(52.2 \%)$ of the children were males, as compared to $47.6 \%$ of their female counterparts. The mean ( \pm SD) age of mothers in years was $27.79( \pm 7.13 \mathrm{SD})$. Most $(54 \%)$ of the mothers were single, while $37.6 \%$ were married. About $37.2 \%$ of the mother had passed their grade 12 while $16.8 \%$ had tertiary education (Table 1 ).

\section{Table 1}


Socio-demographic characteristics of the study participants $(n=250)$. 


\begin{tabular}{|c|c|c|c|}
\hline Characteristics & Frequency & Percentage & Mean \pm SD \\
\hline \multicolumn{4}{|c|}{ Age of child (months) } \\
\hline $0-6$ & 101 & 40.4 & \multirow{4}{*}{$10.53 \pm 8.39$} \\
\hline $7-12$ & 72 & 28.8 & \\
\hline $13-24$ & 55 & 22.0 & \\
\hline $25-36$ & 22 & 8.8 & \\
\hline \multicolumn{4}{|l|}{ Gender } \\
\hline Male & 131 & 52.4 & \\
\hline Female & 119 & 47.6 & \\
\hline Maternal age (years & & & \\
\hline$\leq 19$ & 31 & 12.4 & \multirow{4}{*}{$27.79 \pm 7.133$} \\
\hline $20-29$ & 123 & 49.2 & \\
\hline $30-39$ & 88 & 35.2 & \\
\hline$\geq 40$ & 8 & 3.2 & \\
\hline \multicolumn{4}{|l|}{ Marital status } \\
\hline Single & 135 & 54.0 & \\
\hline Married & 94 & 37.6 & \\
\hline Divorced & 5 & 2.0 & \\
\hline Living with partner & 9 & 3.6 & \\
\hline Separated & 7 & 2.8 & \\
\hline \multicolumn{4}{|l|}{ Education level } \\
\hline Never attended & 1 & 0.4 & \\
\hline Grade $1-4$ & 2 & 0.8 & \\
\hline Grade $5-7$ & 6 & 2.4 & \\
\hline Grade 8 - 10 & 48 & 19.2 & \\
\hline Grade $11-12$ & 58 & 23.2 & \\
\hline Passed grade 12 & 93 & 37.2 & \\
\hline Tertiary & 42 & 16.8 & \\
\hline Employment status & & & \\
\hline
\end{tabular}




\begin{tabular}{|lll|} 
Employed & 62 & 24.8 \\
\hline Unemployed & 188 & 75.2 \\
\hline
\end{tabular}

Almost all mothers (96\%) initiated breastfeeding within one hour after birth, while $3.2 \%$ introduced breastfeeding a day after birth. The majority of mothers (95.2\%) were assisted by nurses to initiate breastfeeding. Exclusive breastfeeding up to six months were practiced by only $7.6 \%$ of mothers. Almost three-quarter of mothers were still breastfeeding at the time of interview while $26 \%$ were no longer breastfeeding. Of all the mother, $68.8 \%$ exclusively breastfed their children up to 2 months while $23.6 \%$ breastfeed their children up to 3 to 5 months. More than three-quarter $(38.8 \%)$ of the mothers chose breastfeeding because it is perfect food for a child. About $16.3 \%$ of mothers stop breastfeeding before 12 months, and the main reason for stopping breastfeeding was going back to school or work (Table 2).

Table 2

Breastfeeding practices $(n=250)$ 


\begin{tabular}{|c|c|c|}
\hline Variables & Frequency & Percentages \\
\hline \multicolumn{3}{|l|}{ Time of initiation breastfeeding } \\
\hline Within one hour after birth & 240 & 96.0 \\
\hline A day after birth & 8 & 3.2 \\
\hline Week after birth & 2 & 0.8 \\
\hline \multicolumn{3}{|l|}{ Assistance of initiation of BF } \\
\hline Nurse & 237 & 95.2 \\
\hline Medical Doctor & 13 & 5.6 \\
\hline \multicolumn{3}{|l|}{ Sources of BF information } \\
\hline Health care professionals & 209 & 91 \\
\hline Parents/parents in law & 2 & 0.9 \\
\hline Media (Magazine, Radio \& TV) & 3 & 1.3 \\
\hline Mom-connect & 15 & 6.6 \\
\hline \multicolumn{3}{|l|}{ Duration of EBF } \\
\hline 0 to 2 months & 172 & 68.8 \\
\hline 3 to 5 months & 59 & 23.6 \\
\hline 6 months & 19 & 7.6 \\
\hline \multicolumn{3}{|l|}{ Breastfeeding status } \\
\hline Still breastfeeding & 185 & 74 \\
\hline Stopped breastfeeding & 65 & 26 \\
\hline \multicolumn{3}{|l|}{ Reasons for choosing BF } \\
\hline Perfect food for a child & 97 & 38.8 \\
\hline Protect child against diseases & 75 & 30.0 \\
\hline Free & 3 & 1.2 \\
\hline Bonding between mother and child & 10 & 4.0 \\
\hline \multicolumn{3}{|l|}{ Breastfeeding frequency } \\
\hline On-demand & 112 & 44.8 \\
\hline On schedule time & 23 & 9.2 \\
\hline At your own time & 50 & 20 \\
\hline
\end{tabular}




\begin{tabular}{|c|c|c|}
\hline \multicolumn{3}{|l|}{ Age of stopping breastfeeding } \\
\hline Less than 1 month & 7 & 2.8 \\
\hline 2 - 5 months & 17 & 6.8 \\
\hline 6 - 12 months & 18 & 7.2 \\
\hline 13 - 24months & 23 & 9.2 \\
\hline \multicolumn{3}{|l|}{ Reasons for stopping breastfeeding } \\
\hline Medical condition & 13 & 5.2 \\
\hline Child refused breast & 10 & 4.0 \\
\hline Going back to school/work & 27 & 10.8 \\
\hline Not enough breastmilk & 8 & 3.2 \\
\hline Another pregnancy & 3 & 1.2 \\
\hline Was the right time to stop breastfeeding & 4 & 1.6 \\
\hline
\end{tabular}

$$
B F=\text { Breastfeeding }
$$

Nearly three-quarter of children (73.6\%) were introduced to complementary foods at the time of interview while $26.4 \%$ were not introduced to complementary foods. Most children (87.5\%) were introduced to complementary food before six months. The majority of children (91.2\%) were given water before six months. The reason for introducing water include: child cries a lot $(70.1 \%)$, advised by parents/parents in law (11.4\%). Few children (9.2\%) had attained minimum dietary diversity (Table 3).

\section{Table 3}

Complementary feeding $(n=184)$. 


\section{Variables}

\section{Age of introducing complementary foods}

1 month

$2-3$ months

$4-5$ months

6 months

Age of introducing water

$0-2$ months

$3-5$ months

6 months and above

Reasons for introducing CF.

Child cries a lot

Insufficient breastmilk

Advised by parents/parents-in-law

Advised by health professionals

It was the right time

\section{Sources of CF information}

Health worker (Nurse, Dietician/Nutritionist)

Parents/parents in-law

Media (Newspaper, Radio, TV)

Peers (friends, colleagues).

\section{Type of CF information received}

Child must eat a variety of foods

Child must eat vegetables and fruit every day

Child must eat meat, eggs as often as possible

Child must start complementary foods at the age of six months

Dietary diversity score

$<4$ food groups

$\geq 4$ food groups

5

1

22

4

4

17
43

142

21

129

70.1

15

21

17

2

8.2

11.4

9.2

1.1

$\begin{array}{ll}7 & 6.5\end{array}$

4.7

0.9

72

20.6

3.7

3.7

90.8

9.2 


$$
C F=\text { Complementary feeding }
$$

The prevalence of underweight, wasting and stunting among children was $3.6 \%, 2 \%$ and $9.2 \%$ respectively. The mean $( \pm S D)$ weight-for-age (WAZ) for total children was $-0.24( \pm 0.871$ SD). The mean ( \pm SD) length/height-for-age ( $(\mathrm{L} / \mathrm{HZ})$ for total children was -0.35 ( $\pm 1.258 \mathrm{SD})$. The mean $( \pm \mathrm{SD})$ weight-forlength/height $(\mathrm{WL} / \mathrm{HZ})$ of total children was $-0.06( \pm 1.049 \mathrm{SD})$. The prevalence of overweight was $1.6 \%$ while 13.2 were at possible risk of overweight. The mean ( \pm SD) BMl-for-age for total children was -0.05 $( \pm 1.064 \mathrm{SD})$. About $1.5 \%$ had moderate acute malnutrition while $6.5 \%$ were at risk of acute malnutrition (Table 4).

\section{Table 4}

Nutritional status of the study participants $(n=250)$ 


\begin{tabular}{|c|c|c|c|}
\hline Z-score classification & Interpretation & Frequencies n (\%) & Mean \pm SD \\
\hline \multicolumn{3}{|l|}{ Weight for age } & \multirow{6}{*}{$-0.24 \pm 0.871$} \\
\hline$<-3 S D$ & Severely Underweight & $0(0)$ & \\
\hline$-3 S D-<-2 S D$ & Underweight & $9(3.6)$ & \\
\hline$-2 S D-<-1 S D$ & Mild underweight & $41(16.4)$ & \\
\hline$-1 S D-+1 S D$ & Normal & $183(73.2)$ & \\
\hline$>+1 S D-\leq+2 S D$ & Possible growth problems & $17(6.8)$ & \\
\hline \multicolumn{3}{|l|}{ Length-for-age } & \multirow{5}{*}{$-0.35 \pm 1.258$} \\
\hline$<-3 S D$ & Severely stunted & $1(0.4)$ & \\
\hline$-3 S D-<-2 S D$ & Stunted & $23(9.2)$ & \\
\hline$-2 S D-<-1 S D$ & Mild stunted & $59(23.6)$ & \\
\hline$-1 S D-<+3 S D$ & Normal length & $167(66.8)$ & \\
\hline \multicolumn{3}{|l|}{ Weight for length } & \multirow{8}{*}{$-0.06 \pm 1.049$} \\
\hline$<-3 S D$ & Severely wasted & $0(0)$ & \\
\hline$-3 S D-<-2 S D$ & Wasted & $5(2)$ & \\
\hline$-2 S D-<-1 S D$ & Mild wasted & $48(19.2)$ & \\
\hline$-1 S D-+1 S D$ & Normal WHZ & $161(64.4)$ & \\
\hline$>+1 S D-\leq+2 S D$ & Possible risk of overweight & $33(13.2)$ & \\
\hline$+2 S D t 0<+3 S D$ & Overweight & $3(1.2)$ & \\
\hline$>+3 S D$ & Obese & $0(0)$ & \\
\hline \multicolumn{3}{|l|}{ BMI for age } & \multirow{6}{*}{$-0.05 \pm 1.064$} \\
\hline$-3 S D t 0<-2 S D$ & Wasted & $6(2.4)$ & \\
\hline$-2 S D$ to $<-1 S D$ & Normal BMI/A & $46(18.4)$ & \\
\hline$-1 S D$ to+1SD & Normal BMI/A & 154(61.6) & \\
\hline$>+1 S D t o<+2 S D$ & Possible risk of overweight & $40(16)$ & \\
\hline$+2 S D t 0<+3 S D$ & Overweight & $4(1.6)$ & \\
\hline \multicolumn{3}{|l|}{ MUAC for age } & \\
\hline$<11 \mathrm{~cm}$ & Severe Acute Malnutrition & $0(0)$ & \multirow[b]{2}{*}{$0.45 \pm 0.77$} \\
\hline $11.0 \mathrm{~cm}$ to $12.5 \mathrm{~cm}$ & Moderate Acute Malnutrition & $3(1.5)$ & \\
\hline
\end{tabular}




$\begin{array}{|lll|}12.5 \mathrm{~cm} \text { to } 13.5 \mathrm{~cm} & \text { At risk of Acute Malnutrition } & 13(6.5) \\ >13.5 \mathrm{~cm} & \text { Well-Nourished } & 184(92)\end{array}$

Of all the children, (37.4\%) who received water were more likely to be underweight as compared to those who did not receive water $(13.6 \%)(p=0.002)$. About $38.1 \%$ of children who received water before 6 months of age were more likely to be stunted as compared to their counterparts $(19.9 \%)(p=0.001)$. About $(18.5 \%)$ of children who received complementary foods were more likely to be wasted as compared to children who did not receive complementary foods $(71.2 \%)(p=0.003)$ (Table 5).

\section{Table 5}

The association between infant feeding practices and anthropometric status of children.

\begin{tabular}{|c|c|c|c|c|}
\hline Variables & Weight-for-age & & df & P-value \\
\hline Introduction of water & Underweight n (\%) & Normal n (\%) & & \\
\hline Yes & $77(37.4 \%)$ & $129(62.6 \%)$ & 1 & 0.002 \\
\hline \multirow[t]{2}{*}{ No } & $6(13.6 \%)$ & $38(86.4 \%$ & & \\
\hline & Height-for-age & & & \\
\hline Age of introducing water & Stunted n (\%) & Normal n (\%) & & \\
\hline 6 months and below & $72(38.9 \%)$ & $113(61.1 \%)$ & 1 & 0.001 \\
\hline \multirow[t]{2}{*}{ Above 6 months } & $11(16.9 \%)$ & $54(83.1 \%)$ & & \\
\hline & Weight-for-height & & & \\
\hline Introduction of CF & Wasted n (\%) & Normal n (\%) & & \\
\hline Yes & $34(18.5 \%)$ & $150(81.5 \%)$ & 1 & 0.003 \\
\hline No & $47(71.2 \%)$ & $19(28.8 \%)$ & & \\
\hline
\end{tabular}

\section{Association between anthropometric status and feeding practices (Logistic regression)}

Children who were given complementary foods one week after birth, the odds of being underweight were 9.00 times as compared to those who were given complementary foods after six months (OR=9.00; $95 \%$ $\mathrm{Cl}=1.325$ - 61.138). However, no association between children who were given complementary foods between the age of 2 to 3 months after birth and underweight ( $\mathrm{OR}=1.067 ; 95 \% \mathrm{Cl}=0.301-3.785)$. 
Furthermore, no association was observed between children who were given complementary foods between 4 to 6 months after birth and underweight (OR=0.642;95\% $\mathrm{Cl}=0.211-1.948)$ (Table 6).

\section{Table 6}

\section{Association between the age of introducing complementary foods and weight-for-age.}

\begin{tabular}{|llll|}
\hline Variables & Weight & & \\
\hline Age of introducing CF & OR & $\mathbf{( 9 5 \% ~ C l )}$ & P-value \\
\hline 1 week after birth & 9.000 & $1.325-61.138$ & 0.025 \\
\hline 2 to 3 months & 1.067 & $0.301-3.785$ & 0.920 \\
\hline 4 to 6 months & 0.642 & $0.211-1.948$ & 0.433 \\
\hline
\end{tabular}

OR: Odd Ratio, $\mathrm{Cl}=$ Confidence Interval, Significance at $\rho<0.05 . \mathrm{CF}=$ Complementary foods

\section{Discussion}

Early initiation of breastfeeding is one of the measures of determining the effective practice of feeding infants and young children, and it is also one of the ten effective steps of breastfeeding practice. The WHO/UNICEF recommended that breastfeeding should be initiated within the first hour after birth [20]. Most mothers in the current study initiated breastfeeding within an hour after birth. This may be attributed to the fact that health professional assists with deliveries and this health professional are the one who also encourage early initiation of breastfeeding within the first hour after delivery. In the study conducted in Ghana, reported that women who were assisted by health professionals to initiated breastfeeding within the first hour of delivery [21]. Several health benefits such as increased ability of the immune system to resist infections, reduction in the risk of diarrhoea and increased survival rate of children have been linked to early initiation of breastfeeding [22].

Despite the benefit of breastfeeding, less than ten percent of children in the current study were exclusively breastfed up to 6 months. Congruently, South African National Health and Nutrition Examination Survey (SANHANES-1) found that seven percent of children aged $\leq 6$ months were exclusively breastfed [23]. Previous studies have reported that exclusive breastfeeding is rarely practiced in South Africa $[5,13,24$, 25,26 ,]. Poor exclusive breastfeeding practice in the current study is due to the fact that most mothers indicated that returning to schools, influence by the family members and insufficient milk as the main reason for terminating breastfeeding and introducing complementary food. Similarly, several studies have also reported going back to school or work, insufficient breastmilk as the main reasons for introducing complementary foods early [15, 24, 27, 28, 29, 30,31]. Despite a high level of awareness by health professionals and Department of Health on exclusive breastfeeding, practicing exclusive breastfeeding is still a problem in many rural areas of South Africa. Exclusive breastfeeding is one of the strategies which can be used to achieve sustainable development goals 1 and 2 (zero hunger, and good health and well-being respectively). 
Even though, WHO/UNICEF recommended that complementary foods should be introduced at six months of age to ensure that the child obtains all the required nutrients. Most mothers in the current study were unable to do this [20]. Congruently, several studies conducted in South Africa reported introduction of complementary foods before the recommended period of six months $[15,32,33,34,35,36]$. Most children were given soft maize meal porridge mixed with water only and this was given as breakfast, lunch, and supper throughout the week. Despite maize meal being fortified with minerals and vitamins, introduction of maize meal as the main or sole solid ingredients during complementary feeding provide adequate energy, fibre, and B vitamins only and is deficient in protein and minerals such as iron, calcium, and zinc. Introduction of variety of food during childhood is necessary to meet the energy and nutrient requirements and prevent deficiencies that could result into undernutrition [37]. Children who are likely to be wasted are those who are weaned only on the maize meal porridge [38].

Appropriate feeding practice during the first 1000 days of life, from conception to two years of age, is a critical period for the promotion of optimal growth, health, and development. In the current study, early introduction of water was associated to underweight and stunting, while introduction of food early was associated to children being wasted. Introduction of solid food may have detrimental effects on the child's growth and development as infant below six months of age have the gastrointestinal track that is not fully developed to digest other solid foods apart from breastmilk. Insufficient intake of quality diet is one of the contributing factors of undernutrition [37, 39]. Timing of introducing complementary feeding is nutritionally crucial as requirements for nutrients are greater during the second half of infancy [38]. Introduction of fluid and food before six months may increase the risk of diarrheal disease, food allergies, hamper optimal growth and development of the child [40,41]. Short-term adverse effects of undernutrition include recurring illness, weakness, delayed physical and mental development, irritability, poor appetite, low weight for age while the long-term adverse effects are short height for age, poor learning ability, poor performance at school and poor general health [42].

\section{Conclusion}

This study reveals that exclusive breastfeeding for the first six months was rarely practiced, as most mothers introduced to complementary feeding before the recommended age. The prevalence of underweight, stunting and wasting among children were of low public concern. Health professionals should promote the use of mass media and South African mom-connect as the platforms that may be utilised more optimally to disseminate information on infant and young child feeding practices to young mothers.

\section{Abbreviations}

BF: Breastfeeding; BMI: Body Mass Index; CF: Complementary Foods; MUAC: Mid Upper Arm Circumference; n: number; OR: Odd Ratio; Cl: Confidence Interval; SD: Standard Deviation

\section{Declarations}




\section{Acknowledgement}

The authors would like to pass a message of appreciation to the mothers and their children for their participation and cooperation. We would like to thank University of Venda, National Research Foundation (NRF) and Nestle nutrition Institute African (NNIA) for funding the project.

\section{Authors' contributions}

Mugware A conceptualized the study, its design, coordination of data collection, data entry and analysis, interpretation of the data and drafting the manuscript. Mushaphi LF and Motadi SA supervised the whole process and review of the manuscript. All authors have read and approved of the final version of the manuscript.

\section{Sources of funding}

This project was supported by University of Venda, National Research Foundation (NRF) and Nestle Nutrition Institute African (NNIA).

\section{Ethical approval and consent to participants}

Ethical approval for the study was obtained from the University of Venda Research Ethics Committee (SHS/19/NUT/01/1503). The permission to undertake the study was obtained from Provincial Department of Health Research Committee, Vhembe district and then clinics. All mothers were informed about the voluntary and anonymous nature of the study and were told that they could withdraw their participation at any time during the study. Mothers were also informed about possible risk before commencement of the study. Informed consents were obtained. Furthermore, the study was conducted in accordance with the principles of the Declaration of Helsinki, Good Clinical Practices, and the laws of South Africa.

\section{Availability of data and materials}

The datasets generated and analysed during the current study are not publicly available online because university has the copyright. The datasets used during the current study are available from the corresponding author on reasonable request.

\section{Conflict of interest}

The authors declare that they have no conflict of interest. 


\section{Authors details}

${ }^{1}$ Department of Nutrition, Faculty of Health Sciences, University of Venda.

\section{References}

1. Kabaran S. Maternal and Child Nutrition: Importance of the First 1000 Days. International Journal of Clinical Nutrition \& Dietetics. 2018;4(2).

2. World Health Organization. Maternal, Infant and Young Child Nutrition. Report. Geneva, Switzerland; 2013. Available from:https://apps.who.int.

3. UNICEF. First 1000 days, the critical window to endure that children survive and thrive.New York; 2017. Available from:https://www.unicef.org.

4. South Africa National Health and Nutrition Examination Survey. Trends in the prevalence of underweight in children aged 4 to 6 years; 2012. Available fromhttp://www.sanhanes-1.ac.za.

5. Mushaphi LF, Mahopo TC, Nesamvuni CN, Baloyi B, Mashau E, Richardson J, Bessong P. Recommendations for infant feeding policy and programs in Dzimauli region, South Africa: results from the MAL-ED birth cohort. Food and nutrition bulletin. 2017;38(3), 428-440.

6. Bailey RL, West Jr KP, Black RE. The epidemiology of global micronutrient deficiencies. Annals of Nutrition and Metabolism. 2015; 66(Suppl. 2), 22-33.

7. Udoh EE, Amodu OK. Complementary feeding practices among mothers and nutritional status of infants in Akpabuyo Area, Cross River State Nigeria. SpringerPlus. 2016; 5(1), 1-19.

8. Molla M, Ejigu T, Nega G. Complementary feeding practice and associated factors among mothers having children 6-23 months of age, Lasta District, Amhara region, Northeast Ethiopia. Advances in Public Health, 2017.

9. Ma'alin A, Birhanu D, Melaku S, Tolossa D, Mohammed Y, Gebremicheal K. Magnitude and factors associated with malnutrition in children 6-59 months of age in Shinille Woreda, Ethiopian Somali regional state: a cross-sectional study. BMC Nutrition. 2016;2(1), 1-12.

10. United Nation System Standing committee on Nutrition. By 2030 end all form of malnutrition and leave no one behind; 2017. Available from.www.unscn.org [Accessed 9th June 2018].

11. District Health Barometer. (2016).Available fromhttp://www.cabsa.org.za [Accessed May 6th, 2017].

12. Gavhi F, Kuonza L, Musekiwa A, Motaze NV. Factors associated with mortality in children under five years old hospitalized for Severe Acute Malnutrition in Limpopo province, South Africa, 2014-2018: A cross-sectional analytic study. PloS one. 2020;15(5), e0232838.

13. South Africa Demographic and Health Survey. Report, National Department of Health (NDoH), Statistics South Africa (Stats SA), South African Medical Research Council (SAMRC), and ICF; 2016. Available on the NDoH website:www.health.gov.za.

14. Mamabolo RL, Alberts M, Mbenyane GX, Steyn NP, Nthangeni NG, Delemarre-van De Waal HA, Levitt NS. Feeding practices and growth of infants from birth to 12 months in the central region of the 
Limpopo Province of South Africa. Nutrition. 2004;20(3), 327-333.

15. Mushaphi LF, Mbhenyane XG, Khoza LB, Amey AK. Infant feeding practices of mothers and nutritional status of infants in Vhembe District in the Limpopo Province. South African journal of clinical nutrition. 2008;21(2), 36-41.

16. Stewart A, Marfell-Jones M, Olds T, de Ridder H. International standards for anthropometric assessment. In The International Society for the Advancement of Kinanthropometry; International Society for the Advancement of Kinanthropometry: Lower Hutt, New Zealand. 2011.

17. World Health Organization. AnthroPlus for personal computers Manual: software for assessing growth of the world's children and adolescents. Geneva, Switzerland: World Health Organization; 2009.

18. FAO, FHI 360. (2016). Minimum dietary diversity for women: a guide for measurement. Rome: FAO, 82.

19. World Health Organization. WHO Anthro for personal computers, version 3.2. 2: Software for assessing growth and development of the world's children [Internet]; Geneva: World Health Organization; 2011. Available from:https://www.who.int/childgrowth/software

20. World Health Organization. Indicators for assessing infant and young child feeding practices: Definitions and measurement methods; 2021. Available from:https://www.who.int/publication.

21. Seidu AA, Ameyaw EK, Ahinkorah BO, Bonsu F. Determinants of early initiation of breastfeeding in Ghana: a population-based cross-sectional study using the 2014 Demographic and Health Survey data. BMC pregnancy and childbirth. 2020;20(1), 1-11.

22. Abie BM, Goshu YA. Early initiation of breastfeeding and colostrum feeding among mothers of children aged less than 24 months in Debre Tabor, northwest Ethiopia: a cross-sectional study. BMC research notes. 2019; 12(1), 1-6.

23. Shisana O, Labadarios D, Rehle T, Simbayi L, Zuma K, Dhansay A. Report for UNICEF: data analysis on infant feeding practices, and anthropometry in children under five years of age: South Africa 2012. Human Sciences Research Council. 2013; 18-19.

24. Doherty T, Sanders D, Jackson D, Swanevelder S, Lombard C, Zembe W, Tylleskär T. Early cessation of breastfeeding amongst women in South Africa: an area needing urgent attention to improve child health. BMC pediatrics. 2012; 12(1), 1-10.

25. Budree S, Goddard E, Brittain K, Cader S, Myer L, Zar HJ. Infant feeding practices in a South African birth cohort-A longitudinal study. Maternal \& child nutrition. 2017;13(3), e12371.

26. Faber M, Laubscher R, Berti C. (2016).Poor dietary diversity and low nutrient density of the complementary diet for 6-to 24-month-old children in urban and rural KwaZulu-Natal, South Africa. Maternal \& child nutrition. 2016;12(3), 528-545.

27. Maclntyre UE, Baloyi PG. Early infant feeding practices of mothers attending a postnatal clinic in GaRankuwa. South African Journal of Clinical Nutrition. 2005; 18(2), 70-75.

28. Zafar M, Fatmi Z, Shafi K. Determinants of child feeding practices in Pakistan; secondary data analysis of demographic and health survey 2006-07. Journal of Medical Nutrition and 
Nutraceuticals. 2014; 3(2), 78.

29. Du Plessis, L. M. (2013). Commitment and capacity for the support of breastfeeding in South Africa: a paediatric food-based dietary guideline. South African Journal of Clinical Nutrition, 26, S120-S128.

30. Rollins NC, Bhandari N, Hajeebhoy N, Horton S, Lutter CK, Martines JC, Group TLBS. Why invest, and what it will take to improve breastfeeding practices?. The lancet. 2016;387(10017), 491-504.

31. Motadi SA, Malise T, Mushaphi LF. Breastfeeding knowledge and practices among mothers of children younger than 2 years from a rural area in the Limpopo province, South Africa. South African Journal of Child Health. 2019;13(3), 115-119.

32. Cape W, Faber M, Benadé S. Breastfeeding, complementary feeding and nutritional status of 6-12month-old infants in rural KwaZulu-Natal. South African Journal of Clinical Nutrition. 2007; 20(1), 1624.

33. Goosen C, McLachlan MH, Schübl C. Infant feeding practices during the first 6 months of life in a low-income area of the Western Cape Province. South African Journal of Child Health. 2014;8(2), 5054.

34. Kavitha S, Nadhiya C, Parimalavalli R. Study of complementary feeding practices among mothers of infants aged six months to one year. Healthline. 2014;5(2), 29-35.

35. Seonandan $\mathrm{P}, \mathrm{McKerrow} \mathrm{NH}$. A review of infant and young child feeding practice in hospital and the home in KwaZulu-Natal Midlands. South African Journal of Clinical Nutrition. 2016; 29(3), 111-115.

36. Ntila S, Siwela M, Kolanisi U, Abdelgadir H, Ndhlala A. An assessment of the food and nutrition security status of weaned 7-12 months old children in rural and peri-urban communities of Gauteng and Limpopo Provinces, South Africa. International journal of environmental research and public health. 2017;14(9), 1004.

37. Masuke R, Msuya SE, Mahande JM, Diarz EJ, Stray-Pedersen B, Jahanpour O, Mgongo M. Effect of inappropriate complementary feeding practices on the nutritional status of children aged 6-24 months in urban Moshi, Northern Tanzania: Cohort study. PloS one. 2021;16(5), e0250562.

38. Semba RD. The rise and fall of protein malnutrition in global health. Annals of Nutrition and Metabolism. 2016;69(2), 79-88.

39. Stewart CP, lannotti L, Dewey KG, Michaelsen KF, Onyango AW. Contextualising complementary feeding in a broader framework for stunting prevention. Maternal \& child nutrition. 2013; 9, 27-45.

40. Kramer MS, Kakuma R. Optimal duration of exclusive breastfeeding. Cochrane database of systematic reviews. 2012; (8).

41. Mitchodigni IM, Hounkpatin WA, Ntandou-Bouzitou G, Termote C, Mutanen M, Hounhouigan, DJ. Complementary feeding practices among children under two years old in west Africa: a review. African Journal of Food, Agriculture, Nutrition and Development. 2018;18(2), 13541-13557.

42. Olodu MD, Adeyemi AG, Olowookere SA, Esimai OA. Nutritional status of under-five children born to teenage mothers in an urban setting, south-western Nigeria. BMC research notes. 2019;12(1), 1-6. 